\title{
La sustentabilidad del cambio social. Factores positivos en la consolidación de las empresas recuperadas por sus trabajadores en la Argentina
}

\author{
Denise Kasparian \\ Julián Rebón
}

RESUMEN: En la Argentina, las empresas recuperadas por sus trabajadores refieren a procesos de reconversión de empresas capitalistas en cooperativas de trabajo originados en la acción colectiva de los asalariados en defensa de su fuente laboral. A partir del interés por las transformaciones que estas empresas han podido sostener y consolidar en el tiempo, el presente artículo se propone analizar los factores positivos para su consolidación en tanto empresas cooperativas. La estrategia metodológica se basa en el análisis singular y comparado de empresas recuperadas. Las técnicas utilizadas son la entrevista semi-estructurada a informantes clave de las empresas, la observación no participante y el análisis documental. En nuestra hipótesis, los principales factores que colaboran positivamente en los logros alcanzados son: los recursos que se heredan de la empresa fallida, la hegemonía de un proyecto cooperativo que le otorga relevancia a la gestión económica, la tenencia legal de los medios de producción, la producción de bienes y servicios competitivos mercantilmente en un marco de intercambios económicos plurales, así como la participación en redes político-sociales.

PALABRAS CLAVE: Cooperativa, Empresa recuperada, Argentina, sustentabilidad.

CLAVES ECONLIT: 017, P47, Z13.

Cómo citar este artículo / How to cite this article: KASPARIAN, D. \& REBÓN, J. (2020): "La sustentabilidad del cambio social. Factores positivos en la consolidación de las empresas recuperadas por sus trabajadores en la Argentina", CIRIEC-España, Revista de Economía Pública, Social y Cooperativa, 98, 213-246. DOI: 107203/CIRIEC-E.98.13940.

Correspondencia: Denise Kasparian, denise.kasparian@gmail.com, ORCID: orcid.org/0000-0002-68618523, y Julián Rebón, julianrebon@gmail.com, ORCID: orcid.org/0000-0001-7457-4400. Instituto de Investigaciones Gino Germani, Facultad de Ciencias Sociales, Universidad de Buenos Aires, Consejo Nacional de Investigaciones Científicas y Técnicas, Argentina. 


\section{EXPANDED ABSTRACT}

\section{The sustainability of social change. Positive factors in the consolidation of enterprises recuperated by their workers in Argentina}

Recuperated enterprises are private companies that are recovered by their workers due to bankruptcy or different types of business crisis. In Argentina, at the beginning of the 21st century, within the framework of an unprecedented widespread crisis, groups of workers confronted the crisis in the companies they worked by resorting to collective action, their emblematic action being the occupation of productive facilities. Such resistance resulted in the advance over the control of production units and the associated management by the employees organized in worker cooperatives. Far from being only an exception or abnormality of the crisis, these processes of reconversion of capitalist companies based on commodity production by associated workers continued developing in the subsequent years. Although they are mostly based on associative work and on the joint ownership of the means of production, recuperated enterprises show variations in terms of their cooperative models, work conditions, and/or sustainability of their production.

In this regard, we pose the following questions: Which are the cases that have achieved the best results as experiences of associative and self-managed work? What factors have collaborated towards their consolidation? This article analyzes the positive factors for the consolidation of these experiences as cooperative companies. The originality of the research lies mainly in two aspects. Firstly, the analysis proposes a comprehensive approach to the subject, that allows knowing the modes in which the set of factors, some of them positively assessed by the existing literature, are developed and combined in the consolidated recuperated enterprises. Secondly, in methodological terms, the original approach provides a systematic analysis of these factors through the comparison of cases at the national level in a field dominated by singular case studies or statistical approaches to the phenomenon.

The theoretical perspective of the article is plural, with an axis of sociological approach to the object of study, seeking to analyze the social, political, and economic conditions favoring the consolidation of change processes in the sphere of production. It is also fed on a dialogue with diverse contributions from the fields of social and solidarity economy, economic sociology, and social change, as well as work anthropology.

The methodology strategy of this work is based on the individual and comparative analysis of 10 recuperated enterprises cases that have reached the cooperative consolidation. We understand cooperative consolidation both in its labor-economic dimension as well as in the associative dimension. We refer to the experiences that have reached productive continuity in time, and that have maintained and created jobs with adequate work conditions, in the framework of the practice of associative and 
self-managed work. Following the suggestions of the methodology literature on this aspect, we sought a thematic and conceptual representation in the selected cases, depicting aspects, attributes, and themes that we consider crucial to the analysis of the consolidation of production units. In this regard, the selection was executed considering a theoretical criterion of maximization of differences in reference to the following variables in enterprises: Sector, region, size measured in number of workers, and period of recuperation. Within the case studies, we incorporated 2 in which the workers' struggle to resist the enterprise's crisis turned into a new enterprise in the same sector. These experiences differ from the rest of the sample in the fact that they do not inherit the productive means or the brand of the failed enterprise. In this sense, while these 2 cases only recuperate the labor group of the original enterprise, we call them "partially recuperated enterprises". Moreover, we selected 4 recuperated enterprises that do not reach consolidation in terms of the proposed conditions to be deemed as control cases. Field work was executed between September 2017 and October 2018. The cases were addressed by means of observations and semi-structured interviews. Additionally, we resorted to documents and articles published in communication graphic media.

Data analysis was carried out as from two channels. On the one hand, we elaborated reports per case with a narrative style that described experiences and systematized the identified positive factors. On the other hand, we created a matrix to compare the social-productive characteristics and the factors identified in each company. This allowed us to establish the general recurrence of the factors, their combination patterns, and their links with the characteristics of the companies.

As regards to the factors that paved the way for these cooperatives to reach cooperative consolidation, the analysis substantiates a number of hypotheses. Firstly, it highlights the availability of resources inherited from the failed company; these are vital as they are the starting point. Secondly, the support and the forged alliances boost the cooperative to overcome the obstacles and to outline both the associative as well as the business project. Good positioning of the products in the market is a defining element in the consolidation of the company. It partners with other exchange principles; particularly with the relations of redistribution by the State. Achieving the rightful ownership of the production unit bestows companies with greater consolidation. Political hegemony within the core of the cooperative is a key factor that provides the direction towards development. In this direction, it is a defining factor that the rightfully leading cooperative project empowers the economic management with production planning, integration and training of the working community, and investment strategies. Lastly, certain environment conditions of the area or industry that the company is in may benefit the development of the cooperative. These general premises must be modified for the cases of partially recuperated enterprises, conceptualized for the first time in this study. In these, the inheritance factor is not so significant, being decisive to achieve the concession of services through negotiation with the State.

The number of hypotheses resulting from this study deserves to be delved into and systematized in future research. None of the recuperated enterprises presented the same intertwining of the abovementioned aspects; each case seemed to represent a social craftwork that paves its own and unique 
path towards sustainability. Though it is true that certain factors impact more directly on the economic success rather than in the associative success, and vice versa, positive effects tend to show in a combined way and on the whole. Both aspects of the life of cooperatives can only be differentiated analytically; in real life they are intertwined and there is no such thing as independent impacts. Precisely, the peculiarity of the consolidated and assessed cases is the awareness of this duality.

KEYWORDS: Cooperative, Recuperated enterprise, Argentina, sustainability. 
Una cooperativa exitosa es la que puede crecer generando muchas fuentes de trabajo. Pero las otras también tienen mérito, las que han logrado permanecer durante todo este tiempo. Para mí, una cooperativa exitosa es la que ha logrado perdurar. (Asociado de la empresa metalúrgica, diciembre

Para nosotros y nosotras, una cooperativa exitosa es aquella que logra el crecimiento personal y grupal de los trabajadores. (Asociada de una de las empresas lácteas, noviembre 2017)

Permanecer ya es exitoso. Después, en medio de eso, puede haber muchas cosas. Momentos buenos y momentos malos. Si dentro de la organización se logra sortear todas estas dificultades que se pasan, y no se desgrana, eso es exitoso. No es exitoso que me pueda llevar 6 mil 07 mil pesos más. (Asociado de la empresa textil, septiembre 2017)

\section{Introducción}

Desde fines del siglo XX, la economía social y solidaria ha recuperado un importante protagonismo en distintas partes del mundo. Ya sea como alternativa de cambio social sistémico frente a la descomposición del socialismo real o como mecanismo paliativo de contención social; y desarrollado por actores tan diversos como sindicatos, grupos políticos radicales, gobiernos de distinto signo políti$\mathrm{co}$, organismos internacionales o iglesias, se han multiplicado cooperativas, mutuales, esquemas de finanzas solidarias, redes de comercio justo y organizaciones comunitarias, entre otras experiencias. ${ }^{1}$

En este marco heterogéneo, las cooperativas de trabajo o de producción ${ }^{2}$ presentan una de las formas teóricamente más rupturistas con la producción capitalista. Esta figura jurídica se integra por colectivos de trabajadores asociados democráticamente que detentan la posesión de los medios de producción (Singer, 2011), tendiendo a la eliminación de la escisión entre trabajadores y propietarios. A pesar de constituirse, habitualmente, como alternativas al desempleo más que al capital (Quijano,

1.- Orientadas por objetivos sociales, estas experiencias presentan entre sí una fuerte heterogeneidad en torno a su visión, organización y redes sociales en las cuales se desarrollan (Pastore, 2006; Williams, 2014). El universo de referencia de la denominada economía social y solidaria va desde formas de emprendedurismo social y alternativas de empleo en nichos específicos de la producción de servicios y bienes (Puentes Poyatos y Velasco Gámez, 2009; Sabín Galán, Fernández Casadevante y Bandrés de Lucas, 2013) hasta alternativas radicales de cambio (De Sousa Santos y Rodríguez, 2011; Wright, 2015). Por esta misma razón, la nominación de los procesos y en qué medida refieren a un objeto común es cuestión de debate (Williams, 2014).

2.- En la actualidad, se estima que en las cooperativas, así como en sus ámbitos de influencia, se crea casi el 10\% del empleo mundial (CICOPA, 2017a). Específicamente, en las más de 250 mil cooperativas de trabajo que existen, se generan casi 11 millones de puestos de trabajo bajo la figura del socio-trabajador (CICOPA, 2017b). 
2011), éstas son planteadas por diversos teóricos del cambio social como una de las vías para avanzar en cambios sistémicos de mayor alcance que habiliten el poder social sobre la producción y el enraizamiento de la economía en la sociedad (Alperovitz, 2006; De Sousa Santos y Rodríguez, 2011; Wright, 2015). En el otro polo, para sus detractores, provenientes de diversas perspectivas teóricas que van desde la microeconomía neoclásica hasta enfoques marxistas, las cooperativas tienden a disolverse o a "degenerar" en su forma social -es decir, se transforman en empresas capitalistasdebido a factores tanto internos, como externos. ${ }^{3}$

En la Argentina reciente, dentro del universo del cooperativismo de trabajo, destacan las empresas recuperadas por sus trabajadores. A inicios del siglo XXI, en el marco de una inédita crisis general, que conllevó una aguda dislocación social, y en contraposición a la pasividad y la individualización del sufrimiento como forma de lidiar con el desempleo, grupos de trabajadores resistieron la crisis de las empresas que los empleaban con base en la acción colectiva, encontrando en la ocupación de los establecimientos productivos su forma de acción emblemática. La resultante de dicha resistencia fue el avance sobre el control de las unidades productivas y la gestión asociada de la producción por parte de los trabajadores organizados en cooperativas de trabajo. Lejos de quedar acotados a una excepcionalidad o anomalía de la crisis, estos procesos de reconversión de empresas capitalistas con base en la producción asociada mercantil de los trabajadores (Rebón y Kasparian, 2018), continuaron desarrollándose en los años subsiguientes. Según los últimos datos disponibles, a octubre del año 2018 eran 384 las empresas recuperadas que atravesaban distintas ramas productivas y ocupaban más de 15 mil trabajadores en 20 de los 24 distritos de la Argentina, con una mayoría en el Área Metropolitana de Buenos Aires (Programa Facultad Abierta, 2018). Si bien, en términos generales, se basan en el trabajo asociativo y la posesión conjunta de los medios de producción (Rebón y Kasparian, 2018), las empresas recuperadas son heterogéneas en sus modelos cooperativos, en las condiciones de trabajo y/o en la sostenibilidad de su producción.

En este sentido, nos interrogamos ¿cuáles son aquellos casos que han alcanzado mejores resultados como experiencias de trabajo asociativo y autogestionado? ¿Qué factores han colaborado en su consolidación? El presente artículo se propone analizar los factores positivos para la consolidación de estas experiencias en tanto empresas cooperativas. ${ }^{4}$ La originalidad de la investigación reside, principalmente, en dos aspectos. En primer lugar, el análisis propuesto plantea un abordaje integral de la temática. Este permite conocer los modos en que el conjunto de los factores, algunos de ellos positivamente ponderados por la literatura existente, se desenvuelven y combinan en las empresas recuperadas consolidadas. En segundo lugar, en términos metodológicos, la investigación reviste un enfoque original al brindar un análisis sistematizado de dichos factores a partir de la comparación

3.- Para una revisión crítica de las distintas variantes de la tesis de la degeneración de las cooperativas, consúltese Dean (2014).

4.- La investigación ha contado con fondos provenientes del proyecto "Factores positivos en el sostenimiento y la consolidación de empresas recuperadas", financiado por el Programa de Cooperativismo y Economía Social en la Universidad de la Secretaría de Políticas Universitarias de la Argentina, y del proyecto PICT "La reproducción ampliada de las empresas recuperadas por sus trabajadores", financiado por la Agencia Nacional de Promoción Científica y Tecnológica de la Argentina. 
de casos a nivel nacional en un campo dominado por estudios de caso singulares 0 aproximaciones estadísticas al fenómeno. En nuestra hipótesis los principales factores que colaboran positivamente en los logros alcanzados son: los recursos que se heredan de la empresa fallida, la hegemonía de un proyecto cooperativo que le otorga relevancia a la gestión económica, la tenencia legal de los medios de producción, la producción de bienes y servicios competitivos mercantilmente en un marco de intercambios económicos plurales, así como la participación en redes político-sociales.

El artículo se estructura del siguiente modo. En primer lugar, se presenta un apartado metodológico. Seguidamente, se desarrolla el enfoque de la investigación, en diálogo con la literatura existente. En tercer lugar, a modo de contextualización del universo de análisis, se caracterizan los logros económico-laborales y asociativos de las experiencias estudiadas 0 , en otras palabras, explicitamos qué implica ser una empresa recuperada consolidada. Luego, procuramos dar cuenta de cuáles son los factores que han favorecido su consolidación como cooperativas. Finalmente, concluimos con una síntesis de los principales hallazgos y compartimos un conjunto de interrogantes que consideramos aportan al fortalecimiento de las experiencias de la economía social y solidaria existentes 0 a desarrollarse en un futuro próximo.

\section{Metodología}

La estrategia metodológica del trabajo se basa en el análisis singular y comparado de casos de empresas recuperadas que han alcanzado la consolidación cooperativa. Nuestra estrategia es instrumental porque no se analiza cada empresa recuperada por su interés intrínseco, sino que, principalmente, este interés es de carácter secundario; sirve a un objetivo ulterior referente a la comprensión de un problema más amplio (Neiman y Quaranta, 2006). La estrategia analítica es dual, dado que, por una parte, propone la reconstrucción singular de cada caso en las principales dimensiones. Y, por la otra, el carácter múltiple del estudio nos permite abordar comparativamente las distintas experiencias en dichas dimensiones, favoreciendo el avance en la generalización analítica (Archenti, 2007).

El trabajo de campo se estructuró en dos etapas. En un primer momento, a partir de entrevistas a informantes clave -entre estos, dirigentes de organizaciones de empresas recuperadas, funcionarios estatales pertinentes al sector y académicos especializados en la temática-, bases de datos disponibles, y estudios existentes sobre la temática -propios y de otros equipos-, se confeccionó un listado preliminar de empresas recuperadas que alcanzan la consolidación cooperativa. Entendemos la consolidación cooperativa tanto en su dimensión económico-laboral como asociativa. Nos referimos a experiencias que alcanzan la continuidad productiva, preservando y creando puestos de trabajo con condiciones adecuadas, en el marco de la práctica asociativa y autogestionada. De este modo, 
constituyen experiencias que tienden a alcanzar la sustentabilidad. Consideramos como empresas que alcanzan la consolidación cooperativa aquellas que:

En lo económico-laboral:

- Presenten continuidad productiva no menor a dos años.

- El colectivo laboral haya crecido o se haya mantenido en cantidad de trabajadores desde el momento de la fundación.

- Los retiros equiparen o alcancen niveles superiores al salario mínimo, vital y móvil.

- Los trabajadores registren aportes previsionales y acceso a cobertura de salud.

En lo asociativo:

- Presenten autoridades electas y realicen asambleas.

- No tengan presencia de trabajadores no asociados.

Luego, sobre la base de dicho listado, se seleccionaron 10 empresas consolidadas. Se estableció como límite la condición de cuatro o más años de antigüedad para la selección de los casos, con el objeto de que sean empresas que hayan superado la etapa fundacional y constituyente. La representatividad de los casos seleccionados no se ciñe a un criterio estadístico en el cual aquellos representan probabilísticamente a algún tipo de cooperativa. Siguiendo las sugerencias de la literatura metodológica al respecto (Archenti, 2007; Neiman y Quaranta, 2006; Stake, 2013), se buscó en los casos seleccionados una representatividad temática y conceptual, captando aspectos, atributos y temáticas que consideramos cruciales para el análisis de la consolidación de las unidades productivas. En este sentido, la selección se realizó tomando en consideración un criterio teórico de maximización de las diferencias referentes a las siguientes variables de las empresas: sector, región, tamaño medido en base a la cantidad de trabajadores, y período de recuperación (Tabla 1). Dentro de los casos de estudio, incorporamos dos en los cuales la lucha de los trabajadores por resistir la crisis de la empresa devino en una nueva empresa en el mismo rubro. Estas experiencias difieren del resto de la muestra en que no heredan los medios productivos ni la marca de la empresa fallida. Al acuñarse la noción de empresa recuperada, la literatura sobre la temática tendió a soslayar estas diferencias entre los distintos procesos de recuperación. Sin embargo, a los fines de analizar la sostenibilidad de las empresas recuperadas, consideramos pertinente visibilizar esta heterogeneidad constituyente. En este sentido, en tanto estos dos casos sólo recuperan el colectivo laboral de la empresa originaria, los denominamos "empresas recuperadas parciales". Adicionalmente se seleccionaron empresas recuperadas que no alcanzan la consolidación en los términos planteados, como casos de control. Con tal objeto se seleccionaron: i) dos casos del sector industrial que alcanzan la consolidación en el campo económico-laboral, pero no en términos asociativos, ii) un caso del sector servicios y uno del sector industrial que logran la consolidación en términos asociativos, pero no en términos económico-laborales.

Se seleccionaron casos de las siguientes ramas de actividad: alimentaria, láctea, metalúrgica, textil, gastronómica, cerámica, frigorífica, comunicación gráfica, servicios educativos, servicios de gestión de residuos, servicios hoteleros, y transporte de pasajeros; y de las siguientes localizacio- 


\section{LA SUSTENTABILIDAD DEL CAMBIO SOCIAL. FACTORES POSITIVOS EN LA CONSOLIDACIÓN DE LAS EMPRESAS RECUPERADAS POR SUS TRABAJADORES EN LA ARGENTINA}

nes: ciudad de Buenos Aires y conurbano bonaerense (región Área Metropolitana de Buenos Aires), interior de la provincia de Buenos Aires, provincia de Santa Fé, provincia de Córdoba y provincia de Entre Ríos (región Centro), provincia de Río Negro y provincia de Neuquén (región Patagonia). Con el objeto de mantener el anonimato de las cooperativas, en la presente exposición no se proporcionan datos desagregados que permitan identificarlas.

\section{Tabla 1. Características de la muestra}

\begin{tabular}{|l|l|r|r|}
\hline \multicolumn{2}{|l|}{} & $\begin{array}{c}\text { Empresas } \\
\text { consolidadas }\end{array}$ & Casos de control \\
\hline Sector de actividad & Industria & 5 & 3 \\
& Servicios & 5 & 1 \\
\hline Región & AMBA & 4 & 2 \\
& Interior de Buenos Aires & 2 & - \\
& Centro & 3 & 1 \\
& Patagonia & 1 & 1 \\
\hline Tamaño & Pequeña (entre 11 y 60 trabajadores) & 4 & 2 \\
& Mediana (más de 60 trabajadores) & 6 & 2 \\
\hline Período de recuperación & Pre-crisis (antes de 2001) & 2 & 1 \\
& Crisis (2001, 2002, 2003) & 3 & 3 \\
& Post- crisis (2004 y en adelante) & 5 & - \\
\hline Total & & 10 & 4 \\
\hline
\end{tabular}

El trabajo de campo se realizó entre septiembre de 2017 y octubre de $2018 .{ }^{5}$ Los casos se abordaron a partir de la realización de observaciones y 34 entrevistas semi-estructuradas. Adicionalmente, recurrimos a documentos y artículos publicados en medios gráficos de comunicación. La entrevista semi-estructurada a informantes clave de las empresas representó la técnica principal utilizada. El diseño de la misma se estructuró en 200 preguntas abiertas en las siguientes temáticas: i) características socioproductivas, ii) situación de origen y principales hitos en la historia, iii) caracterización de la cultura organizativa, iv) participación en redes y organizaciones, v) identificación de subsidios y/o

5.- El relevamiento se realizó en un contexto de alta fluctuación económica caracterizado por una recesión en la parte final del período. Si bien durante el primer trimestre de 2018 se observó un leve crecimiento del PBI del 0,7\% respecto al último trimestre de 2017, a partir del segundo trimestre comenzó un período recesivo, con un decrecimiento del 4,1\% durante el segundo trimestre y del $0,7 \%$ durante el tercero. Así, en comparación al año 2017, el decrecimiento anual fue de 1,4\%. Estos valores negativos fueron más altos en el sector industrial, donde el estimador mensual industrial registró en octubre de 2018 un decrecimiento acumulado anual respecto a igual período del año anterior de $2,5 \%$. Entre las distintas ramas de actividad se registró una importante heterogeneidad; por ejemplo, la industria textil atravesó un decrecimiento del $11,8 \%$ (INDEC, 2018a, 2018b, 2018c). 
financiamientos recibidos y política pública orientada al sector, vi) caracterización de la inserción en el mercado y estrategias económicas, vii) régimen laboral, viii) aprendizajes e innovaciones positivas reconocidos por los informantes, ix) balance global de la experiencia y de su trayectoria por parte de los informantes.

El análisis de los datos se realizó a partir de una doble vía. Por un lado, se confeccionaron informes por caso con un estilo narrativo en donde se describieron las experiencias, estableciendo sus características y logros, y sistematizando los factores positivos identificados. Por el otro, se elaboró una matriz comparativa de las características socio-productivas y los factores identificados en cada empresa. Esto nos permitió establecer la recurrencia general de los factores, sus patrones de combinación, y sus vinculaciones con las características de las empresas.

\section{Sustentabilidad y cambio social}

La perspectiva teórica del artículo es plural, teniendo como eje una aproximación sociológica al objeto, que busca analizar los factores sociales, políticos y económicos que favorecen la consolidación de procesos de cambio en el ámbito de la producción. Abreva en un diálogo con diversos aportes provenientes de la economía social y solidaria (Coraggio, 2008; Hintze, 2013; Pastore, 2006; Vázquez, 2014), la sociología económica (Polanyi, 2007) y del cambio social (De Sousa Santos y Rodríguez, 2011; Wright, 2015), así como la antropología del trabajo (Fernández Alvarez, 2017). Estos aportes nos brindan útiles herramientas teóricas que nos permiten inscribir nuestra investigación sobre las empresas recuperadas consolidadas en una problemática más amplia referida a las condiciones para la sustentabilidad de las cooperativas de trabajo.

Si bien existe un relativamente importante acervo de investigaciones sobre la recuperación de empresas por parte de sus trabajadores (Balladares, 2012; Bialakowsky et al., 2004; Calloway, 2016; Deux Marzi, 2014; Fajn, 2003; Fernández Álvarez, 2007; Hudson, 2011; Kasparian, 2017; Palomino, 2003; Perbellini, 2016; Pizzi y Brunet Icart, 2014; Rebón, 2007; Salgado, 2012), a 18 años de la difusión del proceso, no existe un estudio sistemático que evalúe conjuntamente los factores que favorecen mayores logros y los modos en que se desenvuelven dichos factores. Los antecedentes en la temática muestran que las empresas recuperadas nacen como una estrategia de los trabajadores para defender su inserción ocupacional, es decir, como alternativa al desempleo, siendo la empresa resultante estructurada por esta lógica originaria (Rebón, 2017). Aun cuando aquellos que participan de los procesos lo hagan a partir de una pluralidad de motivaciones y sentidos (Pizzi y Brunet Icart, 2014; Rebón, 2007), dicha lógica es la que articula al conjunto. En términos de la economía solidaria 
(Coraggio, 2008), y en sintonía con los testimonios que inician el presente artículo, se afirma que las recuperadas suelen orientarse a la reproducción -simple o ampliada- de la vida de los trabajadores y sus familias y no a la maximización de la ganancia (Rebón, 2017). Motivaciones más ideológicas y/o más pragmáticas pueden coexistir sin mayores tensiones en la medida en que este objetivo se materialice. Este, a semejanza de lo que ocurre en otras experiencias autogestionarias, convive con otros fines, tales como ampliar la cooperativa a familiares, aportar al desarrollo comunitario o regular la intensidad del trabajo en función de los trabajadores (Morales, Monzón y Chaves, 2003). En este marco, se instala el debate acerca de los parámetros que debieran tenerse en cuenta para abordar la cuestión de la sustentabilidad de las empresas recuperadas en particular, y de los emprendimientos asociativos y autogestionados en general.

La noción de sustentabilidad puede definirse genéricamente como la capacidad de un emprendimiento productivo de perdurar en el tiempo, produciendo sus propios ingresos (Fernández Álvarez, 2017). Frente al criterio de sostenibilidad económica mercantil "estricta" que ordena la consideración acerca de la viabilidad de los emprendimientos productivos en las formaciones sociales capitalistas, diversos autores han delineado nociones alternativas. Coraggio (2008) propone analizar la sustentabilidad de estos emprendimientos a partir de la noción de sostenibilidad socioeconómica. Esto es, en función de la capacidad de los emprendimientos de reproducir la vida de sus miembros, admitiendo en el esquema "subsidios" económicos generalizados a partir del principio de redistribución progresiva por parte del Estado, así como los aportes y recursos basados en relaciones de reciprocidad. Vázquez $(2010,2014)$ sostiene la necesidad de considerar la pluralidad de principios económicos que se ponen en juego, por lo que propone la noción de sostenibilidad plural y colectiva, en contraposición a la autosustentabilidad mercantil. En la práctica, esta perspectiva de sustentabilidad se traduce en un conjunto complejo de políticas, instituciones y recursos que colaboran para la reproducción de estas organizaciones y de los trabajadores que las integran (Hintze, 2013). ${ }^{6}$ Aquí también resulta central el principio de redistribución y, en este sentido, la capacidad política y cultural para construir alianzas y relaciones de fuerza favorables con miras a impulsar políticas públicas que permitan la sostenibilidad colectiva del sector. De Sousa Santos y Rodríguez (2011) postulan que los criterios para evaluar el éxito o el fracaso de las alternativas económicas al capitalismo deben ser gradualistas -es decir moderados-e inclusivos, esto es, no sólo económicos, sino considerando la multiplicidad de dimensiones de lo que éstas generan en clave emancipatoria. En un sentido similar, Fernández Álvarez (2012)

6.- La presencia de otros principios no debe reducirse al ámbito de la empresa. La presencia y el grado de extensión de un sistema de bienestar social público que abarque al conjunto de la población, desmercantilizando parcialmente ciertas necesidades, es un elemento que promueve el campo de la producción cooperativa. En este sentido, en el año 2007 se creó -y en los sucesivos años fue ampliando su coberturala Asignación Universal por Hijo, que se asemeja al salario familiar que perciben los trabajadores asalariados formalizados. Ésta consiste en una asignación mensual por cada hijo menor de 18 años, destinada a trabajadores desocupados, no registrados y autónomos de las escalas más bajas de ingresos. En este sentido, favoreció a una parte significativa de los trabajadores cooperativos. En línea con esto, existen varios estudios que postulan el rol central de la renta básica universal no sólo en la búsqueda de la igualdad social, sino también como promotor de la economía social y el cooperativismo (Wright, 2015), y como elemento central de un nuevo esquema de protección social que desvincule la dignidad humana del trabajo tal como lo concebimos en la actualidad (Moruno, 2018).

CIRIEC-España, Revista de Economía Pública, Social y Cooperativa ISSN: 0213-8093

$N^{\circ} 98 / 2020$, pp. $213-246$ 
señala que la noción de sustentabilidad tiende a opacar la potencialidad de las empresas recuperadas como espacios de construcción colectiva.

En línea con las nociones de sustentabilidad presentadas, diversas investigaciones han dado cuenta de que la tensión que introduce la inserción en el mercado de estas experiencias puede ser abordada limitando el carácter desregulado del mercado o fortaleciendo otros principios de intercambio, como las relaciones de reciprocidad con otros actores y las relaciones de redistribución con el Estado (De Sousa Santos y Rodríguez, 2011; Fernández Álvarez, 2012; Itzigsohn y Rebón, 2015; Wright, 2015). Asil, cabe formular la hipótesis de que la sustentabilidad es favorecida en tanto y en cuanto las cooperativas logren márgenes crecientes de autonomía respecto al mercado a través de la combinación de diversos principios económicos o de regulaciones del mismo que les sean favorables (Deux Marxi, 2014; Kasparian, 2017). En este campo, se le ha dado especial atención a la necesidad de que estas experiencias se inserten en redes de colaboración y apoyo mutuo, integrando procesos más amplios de transformación económica, política y cultural (De Sousa Santos y Rodríguez, 2011; Pizzi y Brunet Icart, 2014; Williams, 2014; Wright, 2015).

Ahora bien, desde nuestra perspectiva resulta insoslayable que la competencia en el mercado, en el marco de una formación social capitalista, ${ }^{7}$ impone condiciones al interior de las empresas, dado que el objetivo ya señalado de reproducción del colectivo de trabajadores se realiza principalmente a través de la producción para el mercado. Esta aseveración ha sido sostenida por múltiples investigaciones acerca de las empresas recuperadas (Balladares, 2012; Bialakowsky et al., 2004; Costa Álvarez, 2008; Hudson, 2011), aunque no necesariamente debe desprenderse una lectura determinista de esta condicionalidad (Deux Marxi, 2014). Aun cuando las condiciones del éxito de las cooperativas no se reduzcan al intercambio mercantil, éstas requieren del uso de la racionalidad instrumental para la planificación y evaluación económica. En cierto punto, las cooperativas deben maximizar el proceso productivo de modo de competir en costos y calidad, y así obtener excedentes que posibiliten constituir capital de trabajo y reinvertir -en reemplazo de maquinaria o renovación tecnológica, por ejemplo- para la capitalización de la unidad productiva. Dicho de otro modo, cierto grado de acumulación es necesaria para sostener la producción, a riesgo de que si esto no ocurre, con el paso del tiempo, se precipite una crisis de la empresa (Rebón, 2017). Difícilmente pueda pensarse que otros principios puedan desplazar al mercado en las empresas recuperadas de la Argentina actual. Las políticas de

7.- A los objetos de este trabajo, siguiendo la perspectiva sociológica que propone Wright (2010), entendemos por capitalismo un modo de producción basado en la propiedad privada de los medios de producción y el consumo de fuerza de trabajo asalariada, en el cual la lógica se orienta por la acumulación de capital y la distribución está mediada por el intercambio mercantil. Las formaciones sociales histórico-concretas constituyen articulaciones e interpenetraciones (hibridaciones) de diversos modos de producción. Las empresas recuperadas representan una forma socioproductiva hibrida que, en aproximaciones previas, conceptualizamos como producción asociada mercantil de los trabajadores. El carácter asociado refiere a la comunidad que, basada en la cooperación voluntaria entre iguales, detenta la gestión y-con limitaciones-realiza la apropiación productiva. El carácter mercantil refiere al tipo dominante de intercambio y a que su lógica -al igual que la pequeña producción mercantil- está orientada al consumo más que a la acumulación. Finalmente, el término trabajadores subraya la composición social y, con ello, la lógica de la producción (Rebón y Kasparian, 2018). 
redistribución suelen ser acotadas y dependen sobremanera de los ciclos políticos, ${ }^{8}$ mientras que las relaciones de reciprocidad, en las condiciones actuales de desarrollo de la economía social en el país, difícilmente logren prácticas sistemáticas significativas que puedan suplir el intercambio en el mercado. En este marco, pensar criterios inclusivos de sustentabilidad en la Argentina actual, en nuestra hipótesis, no puede llevar a soslayar la relevancia central del intercambio mercantil. Así, la pregunta no es cómo estas experiencias son sustentables más allá del mercado, sino cómo son exitosas en el mercado y en qué medida deben y pueden apoyarse en otros principios de intercambio que limiten o complementen lo estrictamente mercantil.

Sumada a la consideración de la pluralidad de principios económicos para la sustentabilidad de las empresas, y en vinculación con la dimensión del poder, De Sousa Santos y Rodríguez (2011) jerarquizan, entre otros elementos, la radicalización de la democracia participativa y económica como factor de éxito en las cooperativas de producción. En tanto la cooperativa es, simultáneamente, una asociación de personas y una empresa operada colectivamente (Vuotto, 1994), se plantea el desafío de elaborar estrategias que permitan adoptar reglas de funcionamiento democráticas, con el adecuado desarrollo de estructuras de gestión operativas y eficaces en el tiempo (Pastore, 2006; Petriella, 1998). Deux Marzi (2014), en su análisis de la consolidación de empresas recuperadas, coloca el foco en la capacidad de afirmar y sostener un rumbo político y económico que consolide relaciones asociativas al interior y articulaciones con otras organizaciones y la comunidad hacia el exterior. La necesidad de la direccionalidad en el proceso guarda una relevancia muchas veces soslayada en la literatura a expensas de la innovación democrática. Desde nuestra perspectiva, no es la radicalización democrática per se el factor de éxito. La dinámica de la toma de decisiones y la capacidad institucional de conservarlas y ejecutarlas es relevante. La existencia de un proyecto que oriente en el mediano plazo a la cooperativa y logre construir acumulativamente también. En otras palabras, lo central es que, en condiciones democráticas, un proyecto cooperativo, que tenga en cuenta el conjunto de desafíos empresariales y asociativos, alcance hegemonía política al interior de la cooperativa y logre desarrollar los mecanismos institucionales y organizativos pertinentes a la materialización del proyecto.

Otro grupo de estudios han establecido sugerentes comparaciones entre las cooperativas y los emprendimientos capitalistas convencionales, destacando aquellos factores que pueden tornar a las primeras más competitivas. Se destaca el compromiso de los trabajadores con la empresa, favoreciendo la flexibilidad y creatividad (Alves, Burdín y Dean, 2016; Burdin, 2014; De Sousa Santos y Rodríguez, 2011; Morales, Monzón y Chaves, 2003; Sabín Galán et al., 2013; Wright, 2015). Junto a la sinergia entre éstas, la orientación flexible al cliente redunda positivamente en la competitividad de las cooperativas (Moyano Fuentes, Puig Blanco y Bruque Cámara, 2008). También, la potencia

8.- Durante la primera década del siglo XXI se registró un importante avance en el desarrollo de instancias estatales y de programas de la política pública -en distintos niveles del Estado- orientados a la problemática de la economía social y las empresas recuperadas en particular (Hintze, 2013). En los últimos años, en el contexto del cambio del ciclo político se registra una inversión de esta tendencia (Hintze, 2018; Hopp, 2017). 
productiva que otorgan al colectivo laboral las relaciones de colaboración, confianza y cooperación a su interior -a semejanza de lo encontrado por Ostrom (2015) para el gobierno de los recursos comunes-, se propone habitualmente como un elemento clave en el desarrollo de los emprendimientos de la economía social y solidaria (Pastore, 2006; Supervielle, 2017).

Finalmente, corresponde situar dos elementos de centralidad que distinguen a las empresas recuperadas de otros tipos de cooperativas en lo que respecta a la cuestión abordada en este artículo. En primer lugar, las empresas recuperadas expresan una vía singular de acceso a los recursos (medios de producción, colectivo laboral, redes de intercambios, entre otros) con base en una compañía prexistente (Fajn, 2003; Fernández Álvarez, 2017; Rebón, 2007). Precisamente, como desarrollaremos a continuación, en las empresas recuperadas, a diferencia de otros tipos de cooperativas, la herencia de activos de la compañía predecesora o fallida, representa la vía central del acceso a los recursos. De esta manera, en nuestra hipótesis, el punto de partida, el tipo y la magnitud de la empresa de origen, así como la situación y el nivel de desestructuración de la misma durante la crisis de la empresa previa, en términos generales, condicionan el desarrollo posterior del proceso. En segundo lugar, la empresa nace de una acción contenciosa que tiende a asumir la forma de un movimiento social (Tilly y Wood, 2010), durante el cual el colectivo laboral de la empresa originaria (o parte de él) se transforma en una asociación de trabajadores que autogestiona la empresa. En este marco, en nuestra perspectiva, el conflicto juega un rol central para que los trabajadores consoliden su identidad colectiva. En la dinámica del conflicto, los trabajadores intercambian, con otras organizaciones y actores, conocimientos y valores que nutren la gestión asociada de la produción y potencian el desarrollo de prácticas autogestivas (Rebón, 2007). No obstante, si bien el conflicto es un momento clave para la formación del actor cooperativo, su prolongación e intensificación pueden tender a debilitar el activo productivo heredado (deterioro de maquinarias, abandono de trabajadores más calificados, pérdida de proveedores, entre otros). De este modo, en ocasiones, estas dos dimensiones específicas de las recuperaciones (herencia y conflicto) pueden tener interacciones negativas.

En suma, un estudio como el propuesto no sólo aporta conocimiento original a la comprensión de las empresas recuperadas específicamente -teniendo relevancia en esta dirección como insumo para la política pública y la intervención social sobre el sector-, sino que también provee un aporte original al campo de estudios sobre cooperativas, al abordar una vía específica a través de la cual éstas pueden establecerse y consolidarse. 


\section{La consolidación cooperativa en los casos analizados}

Las empresas recuperadas analizadas son heterogéneas en sus logros. A continuación, organizamos la exposición de los logros en tres conjuntos referentes a: i) la consolidación del colectivo laboral, ii) las condiciones de trabajo, y iii) la democracia interna. Esta descripción nos permite dar cuenta de las formas que asume la consolidación cooperativa de las experiencias.

En primer lugar, originadas en la necesidad de defender los puestos laborales de sus fundadores, las empresas recuperadas suelen ir más allá, incorporando trabajadores nuevos. En el conjunto de empresas analizadas, solamente una no creó nuevos puestos de trabajo, mientras que en el otro extremo algunas han llegado a cuadruplicar su dotación inicial de trabajadores. Aun tratándose de las empresas más sostenibles del universo de las recuperadas, persiste una limitación recurrente: el crecimiento de trabajadores no logra recomponer los niveles previos a la crisis que origina la recuperación. Las causas del no incremento de los puestos de trabajo se encuentran en un conjunto de factores que exceden lo económico. Ampliar la asociación implica no sólo tomar una determinación que debe ser económicamente sustentable en el tiempo, sino también el desafío de ampliar el principio de comunidad a nuevos integrantes. Por esto, en los casos que incorporan trabajadores, es frecuente la existencia de un período de prueba para alcanzar un mayor conocimiento del futuro asociado. ${ }^{9}$

En general, el ingreso de familiares suele ser el criterio privilegiado para incorporar trabajadores. Otros criterios ponderados tienen que ver con las calificaciones, ser ex - trabajadores de la empresa fallida o personas que hayan colaborado con el proceso de recuperación. Una característica singular de algunos de los casos analizados es que, a partir de la participación en programas estatales o de convenios con organizaciones sociales y/o educativas, han incorporado personas que han estado privadas de la libertad, pasantes de colegios secundarios, jóvenes con discapacidades y/o con consumos problemáticos.

9.- El período de prueba está permitido por la legislación cooperativa, siempre y cuando el trabajador ingrese como empleado en relación de dependencia con todos los derechos laborales correspondientes. La Resolución N³60/75 del INAES permite la contratación de personal por parte de cooperativas de trabajo solamente por períodos acotados y bajo las siguientes circunstancias: a) Sobrecarga circunstancial de tareas por un lapso no superior a 3 meses; b) necesidad de contar con un técnico o especialista para una tarea determinada no pudiendo exceder los 6 meses; c) trabajos estacionales por un lapso no mayor de 3 meses; y d) período de prueba, el cual no podrá exceder de 6 meses. En estos casos, la cooperativa debe inscribirse como empleadora, e incluir a estos trabajadores como empleados, lo que implica asumir todas las obligaciones estipuladas en la legislación laboral vigente. Una vez cumplidos los plazos, la cooperativa no puede seguir contando con el trabajo de los empleados contratados, a menos que los incorpore como asociados. 
En segundo lugar, respecto a las condiciones de trabajo, los procesos de recuperación producen mayores niveles de igualación entre los trabajadores (Rebón, 2007; Salgado, 2012). Adicionalmente a que todos los trabajadores son socios, una de las expresiones más significativas de dicho proceso lo constituye la relativa igualación de los retiros (el equivalente al salario en una empresa capitalista) de los trabajadores. Si bien sólo en dos casos la igualación es absoluta, en el resto los criterios de diferenciación del retiro implican niveles de desigualdad al interior del colectivo laboral muy inferiores a las empresas precedentes. En líneas generales, las empresas consolidadas tienden a utilizar formas de retribución diferenciada en mayor medida que el conjunto de las empresas recuperadas. El último relevamiento disponible a escala nacional mostraba que el universo de recuperadas se dividía en proporciones similares entre quienes retribuían a todos por igual o utilizaban criterios diferenciados basados en atributos tales como la calificación, la jerarquía laboral, la puntualidad o la antigüedad (Programa Facultad Abierta, 2010). Retribuir de modo diferencial puede ser tanto una causa como una consecuencia del éxito. Por una parte, algunas de estas formas pueden asegurar un mayor compromiso del colectivo y un reforzamiento de procesos de calificación. Por la otra, la posibilidad del pago diferenciado sólo es posible en tanto la empresa tenga ingresos suficientes como para habilitar dicha posibilidad.

En dos casos de control, consolidados en lo económico, pero no en lo asociativo, encontramos la emergencia de nuevas formas de retribución basadas en la propiedad. Se trata de empresas particularmente cerradas sobre sí mismas y con baja articulación con la comunidad. Una cooperativa de la industria alimentaria no asoció a tres trabajadores sobre un total de 43 a pesar de contar con antigüedades que superan lo permitido -entre ocho y catorce años de antigüedad-. Estos trabajadores son contratados bajo modalidades asalariadas, y sus ingresos se rigen por los montos del convenio salarial, que son menores a los de los asociados. Otro caso de control, una empresa industrial de la región Centro, nos alerta más nítidamente sobre las tensiones que entraña una cooperativa que se cierra sobre sí misma. En este caso, la cooperativa se conforma únicamente por los 15 socios fundadores y, para evitar el ingreso de nuevos asociados, dicho grupo realiza contrataciones a través de diversas modalidades. Entre ellas, han creado una sociedad comercial destinada a tal fin. Así, las relaciones entre el grupo de los fundadores y los nuevos trabajadores -que los triplican-, cuyas retribuciones son menores, poseen un carácter salarial en su contenido, reintroduciendo relaciones de explotación en el seno de la unidad productiva. ${ }^{10}$

Con relación a los niveles de dichas retribuciones al trabajo, la situación es heterogénea: están aquellas empresas cuyos retiros se encuentran por debajo del nivel del salario promedio de la rama, aunque siempre equiparando o superando el salario mínimo, vital y móvil establecido para cualquier trabajador formal de la Argentina, aquellas que se encuentran al nivel de la rama, y, por último, aque-

10.- Nuevamente, siguiendo la perspectiva sociológica de Wright (2010), entendemos las relaciones de explotación como relaciones sociales asimétricas e inversas, en las cuales un grupo acapara ventajas materiales a partir de apropiarse del esfuerzo laboral-material (excedente) del otro, basándose, para tal fin, en la exclusión de los explotados de la posesión o propiedad de un bien. 
llas que los superan. Un ejemplo en este último sentido es una escuela recuperada de la región AMBA. Ésta ha logrado que las horas extra - programáticas se paguen igual que las horas programáticas, mejorando las condiciones respecto a cualquier otra escuela de gestión privada o estatal. Más allá de esta heterogeneidad, las experiencias están lejos de representar "economías de la pobreza", como algunos autores las han denominado (Salvia, 2007). En cambio, representan formas exitosas de revertir procesos de pauperización y desempleo. Las jornadas laborales de los trabajadores se encuentran entre las legisladas para el trabajo asalariado, y las vacaciones pagas son restituidas luego de los primeros momentos de la recuperación. En ocasiones singulares de recesión económica en la rama de actividad, como el que atravesaban varias empresas al realizar el trabajo de campo, algunas optaron por bajar los retiros o no aumentarlos, en lugar de prescindir o suspender socios. Una de las cooperativas sintetiza perfectamente esta lógica en el siguiente lema estampado en sus camisetas: "El mercado jamás indicará la suerte de ningún trabajador." (Asociado de la empresa textil, septiembre 2017)

Por su origen, asalariados que se convierten en cooperativistas para preservar su puesto de trabajo, los trabajadores suelen estar signados por un horizonte salarial en torno a los derechos laborales. En el marco de dicho horizonte, y ante el vacío legal en el país en cuanto a los derechos laborales de los trabajadores-asociados de cooperativas, las empresas diseñan sus propias estrategias de protección social. Para esto, en la mayoría de los casos, la cooperativa absorbe el pago del monotributo, un régimen contribuyente ideado originalmente para trabajadores autónomos, que incluye el pago de un impuesto, el aporte previsional y la cobertura de salud. Además, si se encuentran en las categorías de ingresos más bajos del monotributo, los asociados perciben la mencionada Asignación Universal por Hijo, equiparable al salario familiar que perciben los asalariados. Marginalmente, en un caso, se descuenta del retiro del trabajador el pago del monotributo, y en el caso del sector educativo, los docentes han optado mantener el régimen previsional del trabajador asalariado. Este último caso representa una novedad en el universo de empresas recuperadas y requiere mayor análisis respecto a las ventajas y desventajas de permanecer en dicho régimen previsional.

En la cobertura de salud se observa una de las mayores deficiencias de estos emprendimientos respecto a la protección social, dado que las empresas suelen cubrir solamente al asociado. En contraposición, en la muestra analizada, tres de las empresas logran cubrir al grupo familiar. En un caso, la cobertura del grupo familiar se complementa con la contratación de un médico. Otras dos cooperativas cuentan con los servicios de un médico a disposición de los trabajadores, denominado en una de las empresas "gabinete de calidad de vida".

Las jubilaciones y el retiro del trabajador de la empresa representan otros de los grandes desafíos de protección social de las recuperadas. Si bien los trabajadores perciben el haber jubilatorio por su aporte al monotributo, el mayor límite lo constituye el hecho de que el pago del monotributo permite acceder a un haber jubilatorio mínimo, cuando varios de los trabajadores de las recuperadas en edad jubilatoria tienen un historial de aportes, en el marco de relaciones asalariadas, mucho más favorable. 
En varios casos, las cooperativas desarrollan distintas prácticas para enfrentar esta problemática. Algunas extienden la percepción del retiro por una cantidad de tiempo determinada (entre 12 y 15 meses 0 "algunos años") y distinta según sean o no fundadores. Otras calculan el valor de la empresa que les corresponde y lo abonan en cuotas, dando la opción de no cobrarlo y colocar a un familiar directo a modo de sucesión o herencia. Estos procedimientos no se encuentran avalados por la ley y algunas empresas los han ido variando a lo largo del tiempo. Como relata un entrevistado:

En el año 2006 se decidió que se retiraran " $x$ " pesos por año de antigüedad, después se pasó a un monto fijo y fueron pasando los años y ya resulta muy bajo. Ahora quieren reformar el reglamento para que sea por porcentaje, por ejemplo, del monto que cobra todos los meses, un porcentaje, y ese porcentaje te lo llevas cuando te vas, en base a lo que vos estás ganando, entonces cada vez que hay un aumento de retiro, aumenta el dinero que vos te llevas por año. (Asociado de la empresa de transporte, junio de 2018)

Además de estos elementos típicos de protección social, las empresas analizadas han avanzado un tramo más en el camino de la seguridad social y del mejoramiento de la calidad de vida de sus trabajadores. Una de ellas, perteneciente a la rama metalúrgica, sumó un comedor para sus asociados dos días de la semana y otra, dedicada a la gestión de residuos, ha participado de un plan de construcción que ha otorgado viviendas para 50 asociados de la cooperativa.

En tercer lugar, estas empresas representan unidades productivas más democráticas que las empresas capitalistas que les precedieron. Son gestionadas por sus trabajadores y no se registra ninguna forma de gerenciamiento por parte de terceros. Una de las características de las empresas recuperadas, en comparación con otras cooperativas, es la relevancia de la dinámica asamblearia, como resultante de su origen en procesos de conflicto social (Pizzi y Brunet Icart, 2014). Esta dinámica permea significativamente a la gran mayoría de las experiencias. Sólo en un caso el uso de la asamblea se restringe a su forma ordinaria obligatoria de aprobación del balance anual 0 a reuniones de mero carácter informativo y no deliberativo. Algunas veces, las asambleas son reemplazadas por reuniones de sector o de consejo de administración ampliado, es decir, abiertas al conjunto de los asociados que deseen participar. Como complemento también se ha instalado la conformación de comisiones de asociados para tratar cuestiones específicas y se ha fomentado la discusión en los sectores de trabajo, frente al diagnóstico de que no siempre la asamblea es el mejor espacio para el intercambio de opiniones y el avance en el trabajo.

Si bien las empresas recuperadas fueron analizadas en sus primeros momentos como laboratorios de democracia directa, con el paso del tiempo la gestión cotidiana ha tendido a asentarse en los consejos de administración. En los casos analizados, observamos poco recambio en las composiciones de los consejos de administración, lo cual no constituye un aspecto negativo per se, pero sí plantea la necesidad de realizar una cierta vigilancia respecto al peligro de la instauración de un clivaje entre dirigentes y dirigidos. En este contexto, la empresa metalúrgica y una cooperativa de 
comunicación gráfica son las únicas que fomentan activa y explícitamente el recambio de consejeros. Respecto a la participación de las mujeres en los cargos de dirección, algunas empresas ya han estipulado la igualdad de género en la conformación de los consejos. Por último, además del consejo de administración, existen instancias intermedias de coordinación de sectores que permiten que la toma de decisiones circule de manera más amplia:

El órgano supremo es el Consejo de Administración, pero hay un organismo que se llama Comité de Coordinación y Control que está conformado por los responsables de área y la oficina técnica. Ese grupo de trabajo lo que hace es trabajar los aspectos técnicos (...) que a lo mejor necesitan de cierto conocimiento muy específico. Entonces, el Comité de Coordinación y Control es el órgano encargado de evaluar y manejar ese nivel de decisión, lo productivo. Una vez resuelto, ese órgano deriva al Consejo de Administración. (Asociado de la empresa metalúrgica, noviembre 2017)

Adicionalmente a las dimensiones reseñadas, queremos destacar que los logros de las cooperativas no sólo se observan con una mirada exclusivamente centrada en el colectivo laboral y sus formas de participación en la gestión, sino también en los modos de impactar en sus comunidades de pertenencia. En línea con las prácticas de compromiso comunitario del cooperativismo (Puentes Poyatos y Velasco Gámez, 2009), la mayoría de las empresas desarrollan actividades de apertura hacia la comunidad, tanto dispersas (donaciones, proyectos educativos y recreativos), como sistematizadas en políticas con una clara proyección social. Entre los casos analizados, identificamos dos cooperativas que destacan por el fuerte enraizamiento en sus comunidades: la textil y la de gestión de residuos. Se trata de cooperativas que, por ejemplo, poseen un área de trabajos socio-comunitarios con un espacio físico propio abierto a la comunidad y trabajadores destinados a dichas tareas, o construyeron un polideportivo y un bachillerato abiertos a los vecinos de la localidad circundante.

En suma, los casos analizados nos muestran que el éxito productivo y la preservación de los puestos de trabajo pueden lograrse, contradiciendo tesis pesimistas existentes en la literatura sobre la autogestión (Dean, 2014; Morales, Monzón y Chaves, 2003), sin derivar en la reversión hacia una forma capitalista o en la degradación de las condiciones de trabajo. No obstante, tal como hemos desarrollado, la situación en este último aspecto es heterogénea y, en ciertas cuestiones, como por ejemplo la protección social (salud y jubilación), la calidad es menor a la del empleo asalariado. 


\section{Los factores que promueven la consolidación cooperativa}

El análisis de los casos nos permite identificar factores que promovieron su consolidación cooperativa. Dichos factores tienen diferentes niveles de recurrencia entre el conjunto de los casos y se combinan de modo singular en cada experiencia. Además, tal como mencionamos en el caso de las retribuciones con criterios no igualitarios, observamos cierto solapamiento entre los logros analizados y algunos de los factores identificados, de modo que los logros se pueden convertir en factores que posibilitan la sustentabilidad de las experiencias. A continuación, presentamos los principales elementos registrados en el análisis de los casos.

En primer lugar, la recuperación está condicionada significativamente por el punto de partida, por lo que podríamos denominar la "herencia", es decir el tipo y la magnitud de recursos que las cooperativas reciben de sus predecesoras. Por definición, en las recuperadas la herencia de activos productivos es la dotación originaria de las cooperativas. Referimos a activos productivos en un sentido amplio, entendiendo como tales al conjunto de los factores que pueden ser utilizados productivamente. Éstos incluyen los instrumentos de producción, las instalaciones, el capital simbólico de la marca, el colectivo laboral y las redes con proveedores y clientes. Esta herencia de activos suele darse sin "heredar" los pasivos de la empresa fallida, dado que no hay continuidad jurídica, aunque en algunos de los casos analizados ciertas deudas con proveedores fueron pagadas para mantener o recuperar las relaciones comerciales. En este marco, impactan negativamente procesos que limiten 0 alteren dicha herencia, como conflictos muy intensos y prolongados o vaciamientos que desestructuren la empresa. Es interesante señalar que en los estudios que encaramos a inicios del proceso, en el año 2003, encontrábamos que las empresas con alta conflictividad, tendían a dar lugar a procesos más igualitarios y de mayor innovación social, que aquellas con baja conflictividad, donde encontrábamos mayores elementos de continuidad, en general, pero también mejor organización productiva (Rebón, 2007). Sin embargo, varias de las experiencias descriptas apuntan que la continuidad inicial puede, en el mediano plazo, alentar la viabilidad productiva sin necesariamente obstaculizar la innovación social. La no existencia de una paralización significativa de la producción se revela como un aliciente central que favorece la viabilidad. Las unidades productivas que están más "completas" empiezan desde una mejor situación, con mayor disponibilidad de recursos, que aquellas que han sido desestructuradas en su conjunto. En otras palabras, la continuidad productiva promueve la sustentabilidad. Concretamente, en muchos casos resultó favorable que los trabajadores heredaran empresas que antes de ser cooperativa tenían productos destacados y reconocidos en el mercado. Esto favoreció su tarea, dado que no se trató de empezar de cero, sino de continuar o recuperar el producto previo. En algunos casos, también la ubicación privilegiada de las instalaciones les permite un mejor acceso al mercado, sobre todo en las empresas de servicios gastronómicos y educativos. El factor herencia 
de activos es muy limitado en las dos empresas recuperadas parciales, dado que sólo heredan el colectivo laboral y, en ocasiones, bienes secundarios provenientes de la fallida.

Otro factor central para el acceso a los recursos que permiten iniciar y consolidar la recuperación es la participación en organizaciones y redes. La participación en federaciones y movimientos de empresas recuperadas y cooperativas, y, en menor medida, sindicatos facilita recursos políticos y económicos para avanzar en el proceso. Excepto un caso, una cooperativa dedicada al transporte de pasajeros, el resto registran participación en estas organizaciones, aunque la misma pueda no ser muy intensa o continua en el tiempo. De estas organizaciones surge una parte significativa del conocimiento de cómo recuperar una empresa y autogestionarla, así como las relaciones políticas y sociales que permiten avanzar en obstáculos tan diversos como acceder a ayudas puntuales en los momentos iniciales, negociar la tenencia legal de la unidad productiva, recibir solidaridad activa ante posibles represiones o incluso acceder a mercados y líneas de subsidio o crédito. También, estas organizaciones representan la fuente primordial para el conocimiento e identificación con ideas vinculadas al asociativismo y la autogestión, así como para el reforzamiento de su identidad como trabajadores, todo lo cual incide en el proyecto cooperativo a desarrollar. ${ }^{11} \mathrm{~A}$ su vez, son un mediador central de las relaciones con el Estado y el sistema político. En clara discordancia con la relevancia otorgada por la teoría (De Sousa Santos y Rodríguez, 2011; Sabín Galán et al., 2013) y algunos análisis sobre la movilización en las empresas recuperadas (Pizzi y Brunet lcart, 2014), las organizaciones de cooperativas no tienen un rol significativo como instituciones económicas para los emprendimientos estudiados. A pesar del desarrollo de algunas experiencias de articulación en red en ciertos rubros con objetivos económicos, la relevancia de las organizaciones cooperativas es centralmente política.

El intercambio mercantil representa un elemento central en las empresas recuperadas. Si bien el objetivo estructurante de la actividad productiva es la reproducción, esto es, el consumo del colectivo laboral, éste se materializa a través de bienes y servicios producidos para el mercado. En tal sentido, las empresas deben desarrollar productos que puedan competir en sus atributos (precio, calidad, singularidad, etc.) en el mercado. El tener productos competitivos es un elemento central. La mayoría de las empresas comercializan una marca propia. En varios casos, como ya señalamos, se trata de marcas que ya tenían instalación y reconocimiento en la etapa previa. Resulta novedoso mencionar que en algunas de las empresas, como nos testimonia una trabajadora, el carácter cooperativo de la producción se vuelve un agregado que es incorporado a la promoción del producto:

La marca ya estaba impuesta en el mercado, y nosotros la mantuvimos con los precios cuidados, justos y con una muy buena calidad, y el éxito en la gente, de también saber que es un producto cooperativo, fruto de nuestra historia de lucha. (Asociada de una de las empresas lácteas, noviembre 2017).

11.- En este sentido, la cooperativa de transporte de pasajeros que, tal como mencionamos, es el único caso que no presenta experiencia de participación en organizaciones de empresas recuperadas, cooperativas o sindicatos, tampoco registra prácticas asamblearias significativas, más allá de la asamblea ordinaria anual, ni articulaciones con el entramado comunitario. 
En algunos casos, incluyen a otras cooperativas como proveedores y/o clientes relevantes. Varias de las empresas del interior del país tienen como estrategia comercial concentrarse en los mercados regionales o locales donde encuentran mejores condiciones para competir. En algunas empresas se alcanza a diversificar la producción para no depender de un número reducido de productos. Por último, son pocos los casos que tienen venta directa de la producción. Una cooperativa láctea del interior de la provincia de Buenos Aires es un caso interesante en este sentido, dado que logró abrir diez puntos de venta en su área de influencia, otorgándole esto mayor margen de rentabilidad y control de los precios de sus productos. El análisis nos permite señalar que las dos recuperadas parciales siguen una dinámica de inserción diferencial en el mercado. En ambos casos, la venta exitosa de su producción pasa por obtener la concesión de servicios por parte del Estado. Estas concesiones le otorgan una previsibilidad y continuidad en el tiempo que las diferencia del otro conjunto de empresas recuperadas.

Más allá de la relevancia central del intercambio estrictamente mercantil, el desenvolvimiento de las cooperativas se complementa con el desarrollo de otros principios de intercambio (Polanyi, 2007). El más relevante entre éstos es la redistribución desde el Estado, que se enmarca en un conjunto más amplio de acción estatal sobre el sector. El apoyo estatal incluye soportes políticos y económicos para la resolución de obstáculos diversos, en ocasiones resultantes de una dinámica de confrontación y negociación entre el Gobierno y los trabajadores organizados. El apoyo político es central para avanzar en la tenencia de la unidad productiva y el reinicio de la producción (negociación judicial, expropiaciones de inmuebles, obtención de matrícula como cooperativa y habilitaciones comerciales, etc.). Por otra parte, todos los casos estudiados han recibido financiamiento estatal. Estas relaciones de redistribución desde el Estado suelen representar un soporte clave para realizar alguna inversión necesaria o para enfrentar momentos críticos del ciclo de recuperación, y en algunos casos, para acceder a la compra del inmueble. No obstante, los casos analizados dan cuenta de que esta situación no ha dado lugar a una relación de dependencia económica de la política pública. Por ejemplo, en el caso de la metalúrgica, incluso se piensa al Estado como socio estratégico, en clara diferenciación con una visión que tiende a establecer relaciones de dependencia con el mismo:

Por eso, cuando vienen de los ministerios, cuando tenemos las reuniones, nosotros decimos que las cooperativas no queremos que el Estado nos venga a resolver todos los problemas, pero sí un socio estratégico para la renovación de grandes productos, líneas nuevas. Porque son inversiones gigantes las que tenemos que hacer pero...lo cotidiano, lo que podemos ir resolviendo, también las cooperativas tenemos que ser capaces de resolver porque si no dependemos siempre de que nos ayuden. Tuvimos 15 años para desarrollarnos, para crecer, y 12 años con un Gobierno que no nos molestó para nada, que nos dio mucha ayuda y no fuimos capaces dentro de todo ese contexto...También tuvimos que tener autocríticas de las cooperativas. (Asociado de la empresa metalúrgica, diciembre 2017) 
En otros casos, una política pública de regulación de un mercado clave para la actividad resulta central: en la empresa de comunicación gráfica la regulación del precio del papel es sumamente beneficiosa. En los casos de las recuperadas parciales, la decisión política tomada por instancias del Estado es clave para acceder a las concesiones de los servicios que le dan inicio a las actividades productivas de las cooperativas. Por último, en varias experiencias se desarrollan programas y proyectos de transferencia e innovación con universidades, colegios públicos y otros organismos de ciencia y técnica que, guiados por diversos principios de intercambio, representan un aporte para la resolución de problemas socioproductivos. En suma, en consonancia con la literatura existente, el apoyo estatal es relevante para los procesos analizados, pero no se transforma, más allá de las etapas primarias, en la fuente de su sustentabilidad.

Por otra parte, el apoyo de la comunidad local también es un elemento clave en la mayoría de los emprendimientos. Éste incluye tanto la solidaridad afectiva (Fernández Alvarez, 2017) que espontáneamente protagonizan vecinos, como aquella desarrollada por diversas instituciones de la sociedad civil y política. Este soporte es particularmente relevante en las ciudades pequeñas, aunque muchas veces no esté exento de divisiones o controversias en los primeros momentos. La reciprocidad, presente en donaciones, trabajo voluntario o movilizaciones de vecinos y organizaciones hacia los trabajadores y su emprendimiento, colabora para afrontar las etapas iniciales. Así, por lo general, muchas de las articulaciones no mercantiles de las cooperativas con su entorno social son percibidas y presentadas por los trabajadores como una devolución del apoyo recibido en la etapa inicial. Corresponde señalar que éstas y otras formas de intercambios por reciprocidad no suelen alcanzar sistematicidad, teniendo una relevancia mucho menor en la vida de las cooperativas que las alcanzadas por las relaciones de redistribución, y por supuesto, por el intercambio mercantil.

Un elemento fundamental que otorga estabilidad a la cooperativa y favorece la capitalización en la unidad productiva es la tenencia legal del inmueble y los instrumentos de producción. Desde los comienzos de los procesos de recuperación de empresas esta cuestión fue considerada una limitación a resolver a futuro. Sin embargo, en la actualidad son pocos los casos que han logrado alcanzar la propiedad (Rebón y Kasparian, 2018). Entre las empresas consolidadas la situación es distinta. En la mitad de los casos se logró la propiedad plena, con base en mecanismos tales como la compra, la ejecución de leyes de expropiación o incluso en un caso, la construcción de un nuevo establecimiento. En la otra mitad se alcanzaron diversas formas de posesión, tales como alquileres o procesos de expropiación no concluidos. En algunos casos se dan situaciones mixtas: compras de instrumentos de producción y alquiler o cesión por comodato de las instalaciones. En suma, más allá de las modalidades, todas las cooperativas estudiadas alcanzaron la tenencia legal. En términos generales, esta tenencia le da previsibilidad al proceso y favorece que la asociación de trabajadores se concentre en la producción. ${ }^{12}$ Alcanzar la propiedad plena fortalece el proceso y promueve el acceso a convertirse

12.- Uno de los casos de control, exitoso en lo cooperativo y deficitario en lo económico-laboral, muestra la relevancia de esta variable. La cooperativa de servicios analizada no logra alcanzar de modo estable la tenencia legal de las instalaciones, lo cual produce alteraciones en la prestación del servicio por las reiteradas amenazas de desalojo. Paralelamente, la precariedad de la tenencia promovió la falta de todas las inversiones necesarias para el mantenimiento de las instalaciones por la imposibilidad de acceso a subsidios y créditos, así como de incentivo por parte de los trabajadores. El deterioro de las instalaciones retroalimentó la crisis productiva.

CIRIEC-España, Revista de Economía Pública, Social y Cooperativa ISSN: 0213-8093

$N^{\circ} 98 / 2020$, pp. $213-246$ 
en sujetos de crédito, que efectivamente se alcanza en algunos casos. Sin embargo, sólo la mitad de las empresas han tomado crédito. Esto no sólo se debe a problemas de acceso, sino que también incide la existencia de una aversión al crédito entre los trabajadores y sus organizaciones, por el propio origen de la empresa nacida de la quiebra de una predecesora y la historia económica del país. Uno de los principales dirigentes de movimientos de empresas recuperadas nos compartía: "El crédito no sirve, salvo para cosas muy puntuales. Es mejor hacerte vos un colchón. En Argentina te digo. Haces un colchón vos, cuídalo y después lo comprás." (Referente de movimiento de empresas recuperadas, septiembre 2017).

Queremos señalar un elemento central que se encuentra poco trabajado en la literatura disponible y que involucra varios de los aspectos ya reseñados. Nos referimos a la hegemonía política de un proyecto, personificada habitualmente a través de liderazgos de referentes. La hegemonía, entendida como el dominio sostenido en el tiempo de un proyecto con base en el consenso activo de los asociados, es un elemento presente en prácticamente la totalidad de las cooperativas estudiadas. Su relevancia marca la importancia de la continuidad en la línea de conducción como un elemento que estabiliza la empresa y le permite crecer en una direccionalidad. El tipo de unidad socioproductiva resultante está muy influido por la clase de proyecto de empresa que el grupo legítimamente dominante lleve adelante. En los distintos casos, el elemento común que atraviesa las experiencias es que se trata de proyectos cooperativos, donde se le otorga una fuerte relevancia a la gestión económica como modo de alcanzar la reproducción del colectivo laboral. Si bien pueden incorporar de modo diferencial en su proyecto asociativo elementos de innovación o de articulación con otros actores y el entorno social y político, todos tienen un eje importante de política empresarial.

El lema fue: si esto funcionó durante noventa años y se cae es culpa nuestra, no es por ninguna otra razón, es porque no pudimos gestionar. Entonces sabíamos que teníamos que ofrecer un buen servicio, que la escuela tenía que estar pintada, que tenía que estar actualizada, que tenía que haber innovación, y que todas esas cosas no son malas palabras, y que no. Todo lo contrario. Y lo otro era que no podíamos estar todo el tiempo mirándonos hacia adentro, en el sentido de que el elemento central de la cooperativa era generar trabajo y mejorar nuestra posición de trabajo. Tampoco nos parecía bien, si tenemos que estar cobrando durante cuatro años una miseria. De hecho, conseguimos cosas que son reivindicaciones históricas en el marco educativo y que las tenemos nosotros solos, por ejemplo, que las horas extra-programáticas se pagan igual que las horas programáticas. (Asociado de la empresa de servicios educativos, octubre 2018)

Esto contrasta con algunos casos de empresas recuperadas muy emblemáticas en términos políticos pero que son orientadas por proyectos en donde lo político soslaya a lo económico. Entre los casos analizados no priman experiencias referentes del movimiento de empresas recuperadas. Este problema es muy patente en el caso de una de las empresas utilizadas como caso de control. Esta fábrica, referente de una de las organizaciones del movimiento de empresas recuperadas, consiguió 
acceder gratuitamente a la propiedad de la planta por medio de una expropiación resultante de la lucha y movilización de los trabajadores. En origen, la planta se encontraba relativamente en buen estado y tenía productos muy destacados en el mercado. Sin embargo, el predominio de objetivos políticos generales a expensas de lo productivo condujo a su descapitalización y a una situación de aguda crisis interna cuando visitamos la planta. Como modo de mostrar públicamente al conjunto del movimiento el éxito de su política de control obrero, la empresa priorizó mejores retiros y más incorporaciones por sobre una política de reinversión de excedentes, o la gestión y lucha política sin una contraparte en la gestión económica y organizativa. En el siguiente testimonio de una integrante del consejo de administración, se expresa una visión autocrítica de una política de empresa centrada en el mero reclamo al Estado:

Yo con el gobierno no estoy tan enojada, porque, es más, creo que nos han ayudado muchísimo, y que el problema, en realidad, somos nosotros. Si nosotros hubiéramos mostrado una rentabilidad, el gobierno hubiera sido distinto. También la situación. Pero no perduramos en el tiempo porque cada vez estamos en peores condiciones. Tiempo atrás, nos dieron una ayuda de diez millones [de pesos], y no la vimos reflejada en las máquinas. Hicimos una compra de repuestos de diez millones [de pesos] y no lo notamos en ningún lado, fue un desastre la compra, compramos re mal, compramos muchísimas cosas mal. (Asociada de una de las empresas industriales de control exitosa asociativamente, noviembre de 2017)

Estrechamente vinculada a la dimensión anteriormente descripta, en los proyectos cooperativos que alcanzan la hegemonía política registramos la existencia de estrategias de inversión y reinversión como modo de mantener los instrumentos de producción, evitar la obsolescencia tecnológica y lograr incorporar nuevas tecnologías. Sin embargo, resulta relevante mencionar que en el caso específico de la cooperativa de la rama gastronómica, la baja necesidad de inversiones es un aliciente para el desenvolvimiento de la empresa. Éste podría ser el caso de varias empresas del rubro gastronómico.

También vinculado con el proyecto de empresa, el colectivo laboral es otro elemento central para alcanzar la estabilidad y la consolidación de la capacidad productiva. La construcción de una hegemonía política se asienta sobre el consenso activo de colectivos de trabajadores organizados y cohesionados. El reconocimiento de una buena cohesión y clima laboral en varias empresas está asociado a la presencia de estrategias de integración del colectivo laboral, tales como actividades recreativas por fuera del horario de trabajo o espacios de integración de los nuevos o futuros socios. En el reconocimiento del rol que juegan la participación del colectivo de trabajadores y la construcción de una identidad común en el proyecto de empresa radica un elemento clave del desarrollo sustentable de una organización de este tipo (Chosco Díaz, Fardelli Corropolese y Anzoátegui, 2017). De este modo, la consolidación del colectivo laboral no sólo mejora las condiciones de vida de los trabajadores en términos individuales, sino que redunda en la sustentabilidad del proyecto colectivo. Como ya señalamos, prácticamente la totalidad de las empresas ha desarrollado sistemas de diferenciación de retiros. Una de las motivaciones reconocidas por los entrevistados en la elaboración de dichos 
criterios de retiro, además del practicar una distribución que consideran "más justa", es estimular la responsabilidad, el compromiso, la capacitación y la permanencia de los asociados. También destaca positivamente la existencia de niveles adecuados de calificación laboral y de valoración de la misma. La preocupación por mejorar las calificaciones a través de la formación, el ingreso de profesionales al colectivo laboral o la incorporación de asesoramiento externo en los casos en que esto no es posible en el corto plazo, constituyen elementos significativos de muchas de las cooperativas. En consonancia con la literatura existente (Burdin, 2014; De Sousa Santos y Rodríguez, 2011; Moyano Fuentes, Puig Blanci y Bruque, 2008; Wright, 2015), la presencia de una organización flexible del trabajo representa una ventaja productiva de estas cooperativas, dado que promueve una predisposición al cambio que habilita la polivalencia de tareas o ajustes en la jornada laboral, entre otros cambios, cuando es preciso. Finalmente, destaca la relevancia que le otorgan las cooperativas a la construcción y consolidación de las normas de regulación del trabajo, así como la existencia de dispositivos, que de modo gradual y legítimo, favorecen su cumplimiento.

Por último, hay un conjunto de elementos de contexto -condiciones de contorno- que favorecen la sostenibilidad de las experiencias y que no suelen ser tenidos en cuenta en los análisis sobre la temática. En primer lugar, en casos puntuales, la localización brinda ventajas de costos o de reconocimiento social de la empresa que favorecen su viabilidad. Por ejemplo, en el caso de una cooperativa de la rama frigorífica, cambios en la categorización de la zona como libre de aftosa mejoró su competitividad. En otras situadas en ciudades intermedias, la localización les brinda más posibilidades de articulación -más difíciles en otro contexto- con clientes, proveedores y otros actores, dado el entramado comunitario local o le reduce costos frente a otras empresas externas para competir en el mercado local. Otro elemento que merece más desarrollo que el aquí alcanzado, son las condiciones económicas de la rama. La existencia de un proceso de expansión en la rama es un elemento muy significativo, sobre todo en el momento posterior a la recuperación, para la viabilidad de la experiencia. ${ }^{13}$ Más allá de la relevancia de las condiciones de contorno, corresponde señalar que para poder explicar la sustentabilidad de un caso, éstas deben ser analizadas en un marco de interacción con el conjunto de los factores internos de la empresa, previamente analizados.

13.- La fuerte expansión económica vinculada al dinamismo del mercado interno fue un gran aliciente para la consolidación general del proceso en el período posterior a la crisis (2003-2007), luego de alcanzarse el pico de recuperaciones (Rebón, Kasparian y Hernández, 2016). 


\section{Tabla 2. Factores positivos en la sustentabilidad de las empresas recuperadas}

\begin{tabular}{|c|c|}
\hline Dimensiones & Factores \\
\hline Recursos heredados & $\begin{array}{ll}\checkmark & \text { Tipo y magnitud de recursos. } \\
\checkmark & \text { Buen posicionamiento previo del bien o el servicio en el mercado. } \\
\checkmark & \text { Conflicto breve o bajo. } \\
\checkmark & \text { Estado de la unidad productiva originaria. } \\
\checkmark & \text { Retención de trabajadores calificados. } \\
\checkmark & \text { No interrupción significativa de la producción. }\end{array}$ \\
\hline Participación en organizaciones & $\begin{array}{ll}\checkmark & \text { Organizaciones de empresas recuperadas y/o cooperativas. } \\
\checkmark & \text { Sindicatos. }\end{array}$ \\
\hline Producto en el mercado & $\begin{array}{ll}\checkmark & \text { Producto competitivo mercantilmente. } \\
\checkmark & \text { Marca propia principal producto. } \\
\checkmark & \text { Posicionamiento como marca cooperativa. } \\
\checkmark & \text { Venta directa. } \\
\checkmark & \text { Diversificación de productos. } \\
\checkmark & \text { Concesión de servicio. } \\
\checkmark & \text { Intercambios con otras cooperativas. } \\
\end{array}$ \\
\hline Estado y política pública & $\begin{array}{ll}\checkmark & \text { Procesos de redistribución desde el Estado. } \\
\checkmark & \text { Programas con establecimientos educativos y organismos de ciencia y } \\
& \text { técnica. } \\
\checkmark & \text { Apoyo político. }\end{array}$ \\
\hline Apoyo comunitario & Relaciones de reciprocidad con vecinos e instituciones locales. \\
\hline Legalidad de la tenencia & $\checkmark \quad$ Acceso a la tenencia legal del inmueble y las maquinarias. \\
\hline Hegemonía política & $\begin{array}{l}\checkmark \quad \begin{array}{l}\text { Continuidad de un grupo y/o proyecto en la conducción legítima de la } \\
\text { cooperativa. }\end{array} \\
\checkmark \quad \text { Proyecto cooperativo que le otorga relevancia a la gestión económica. }\end{array}$ \\
\hline Inversiones & $\begin{array}{ll}\checkmark & \text { Políticas de capitalización: mantenimiento de maquinarias e inversiones. } \\
\checkmark & \text { Acceso a crédito. } \\
\checkmark & \text { Baja necesidad de inversiones. }\end{array}$ \\
\hline Colectivo laboral & $\begin{array}{ll}\checkmark & \text { Políticas de integración del colectivo laboral. } \\
\checkmark & \text { Criterio de retribución diferenciado. } \\
\checkmark & \text { Formación y capacitación. } \\
\checkmark & \text { Relevancia de normas de regulación del trabajo y dispositivos de cumpli- } \\
& \text { miento de las mismas. } \\
\checkmark & \text { Flexibilidad en las condiciones de trabajo. } \\
\checkmark & \text { Incorporación o formación de profesionales. } \\
\checkmark & \text { Asesoramiento externo. } \\
\end{array}$ \\
\hline Condiciones de contorno & $\begin{array}{ll}\checkmark & \text { Localización en una zona favorece ventaja productiva u organizativa. } \\
\checkmark & \text { Contexto económico positivo de la rama en la etapa posterior a la recu- } \\
\text { peración. }\end{array}$ \\
\hline
\end{tabular}




\section{Reflexiones finales}

En el amanecer del siglo XXI en la Argentina, la difusión de las empresas recuperadas nutrió el repertorio de acción colectiva de los trabajadores para enfrentar el cierre de las unidades productivas. En los casos que analizamos, esta herramienta se reveló como exitosa en la defensa del puesto de trabajo y en la reversión de procesos de pauperización. La defensa de la fuente laboral condujo a innovaciones en el campo productivo, articulando de nuevo modo trabajo y propiedad, democracia y producción, individuo y colectivo, empresa y entorno social.

Las cooperativas abordadas en este estudio logran consolidarse cooperativamente. El objetivo de las experiencias está centrado en la reproducción del propio colectivo laboral. Los casos analizados muestran una tendencia a ampliar dicho colectivo de trabajo. No obstante, los límites de esta tendencia se muestran en que en la mayoría de los casos los puestos laborales no alcanzan los niveles que tenían en las compañías fallidas previamente a los procesos de crisis. Por otra parte, son empresas equitativas en su concepción, exhibiendo los retiros una muy baja desigualdad. Como vimos, el nivel de los retiros es heterogéneo, pero en todos los casos supera al salario mínimo, vital y móvil. Las empresas también han desarrollado mecanismos de protección social para complementar el déficit de protección que poseen los trabajadores de cooperativas de trabajo. Sin embargo, en términos generales, esta protección es más débil que la de los asalariados formales. Las experiencias muestran también un enriquecimiento del campo de acción de los trabajadores, incorporándose los mismos a la toma de decisiones en la empresa a través de diversos mecanismos de democracia directa y representativa. Finalmente, las cooperativas, en su mayoría, tienen una relación abierta con la comunidad, incorporando distintas experiencias de articulación no mercantil con el entorno social. ¿Qué tan extendidos al conjunto del universo de las empresas recuperadas son estos logros?

Los datos disponibles no permiten hacer afirmaciones con certeza. En nuestra hipótesis, experiencias como las analizadas son una minoría en el conjunto del proceso, en particular con relación al componente económico-laboral. Esto se ha acentuado en los últimos años, por el cambio en la orientación de la política económica general y de las políticas públicas destinadas al sector, a partir del gobierno de Mauricio Macri (2015-2019). El exponencial aumento de las tarifas de los servicios públicos, la apertura de importaciones y la falta de dinamismo del mercado interno, junto a mayores restricciones en las políticas para el sector, representan condiciones muy negativas para las empresas recuperadas, registrándose en el año 2018, por primera vez, un descenso de la cantidad de trabajadores de empresas recuperadas, aun cuando se registre un aumento en la cantidad de empresas. ${ }^{14}$

14.- Si se compara la cantidad de empresas con las existentes al momento de la asunción del gobierno de Macri en diciembre de 2015, encontramos que ha crecido el número de casos (384 contra 367), pero que ha disminuido el número de trabajadores (de casi 16.000 a poco más de 15.500) (Programa Facultad Abierta, 2018). 
Incluso en varios de los casos analizados, el cambio en las condiciones de contorno al momento del trabajo de campo había impactado negativamente, retrayendo el nivel de ingresos o limitando la expansión productiva.

Con relación a los factores que les permitieron a las cooperativas alcanzar estos logros económicos y sociales, el análisis precedente fundamenta un conjunto de hipótesis. En primer lugar destaca la disposición de recursos que se heredan de la empresa fallida; éstos son determinantes porque configuran el punto de arranque. En segundo lugar, las alianzas y apoyos alcanzados promueven que la cooperativa pueda ir resolviendo los obstáculos que encuentra y que delinee un proyecto, tanto asociativo, como empresarial. El buen posicionamiento de los productos en el mercado es un elemento definitorio en la consolidación de la empresa. Éste se complementa con otros principios de intercambio, en particular con relaciones de redistribución desde el Estado. Alcanzar la tenencia legal de la unidad productiva le otorga a las empresas mayor consolidación. La hegemonía política al interior de la cooperativa es un factor central que aporta direccionalidad al desarrollo de la cooperativa. En esta dirección es definitorio que el proyecto de cooperativa legítimamente dominante le otorgue relevancia a la gestión económica, con estrategias de planificación de la producción, integración y capacitación del colectivo laboral y realización de inversiones. Finalmente, ciertas condiciones de contorno para la zona o rama en la que se ubica la empresa pueden favorecer el desarrollo de la cooperativa. Estos postulados generales deben ser modificados para los casos de empresas recuperadas parciales, conceptualizados por primera vez en este estudio. En estos, el factor herencia no es tan significativo, siendo determinante lograr la concesión de servicios a través de la negociación con el Estado. El conjunto de hipótesis alcanzadas en este estudio merece ser profundizado y sistematizado en futuras investigaciones.

En ninguna de las empresas recuperadas las dimensiones anteriormente señaladas configuran el mismo entramado; cada caso pareciera representar una artesanía social que construye su propio y singular camino a la sostenibilidad. Si bien ciertos factores impactan más directamente en el éxito económico que en el asociativo, y viceversa, los efectos positivos se suelen producir en el conjunto y de forma combinada. Ambas dimensiones de la vida de las cooperativas sólo pueden diferenciarse analíticamente; en el campo de lo real se encuentran interrelacionadas y no existen impactos independientes. Justamente la peculiaridad de los casos consolidados analizados es la conciencia de esta dualidad. Asimismo, como referimos previamente, se observa una dinámica de recurrencia entre los logros y los factores, que permite que algunos logros se potencien al constituirse en factores del éxito. Ahora bien, resta problematizar la contracara de algunas de las dimensiones identificadas en su impacto en términos cooperativos. Éstas pueden dar lugar a diversas tensiones en el desarrollo de la vida cooperativa. Por un lado, la hegemonía política prolongada puede ser muy efectiva al perfilar una orientación estratégica, pero, en el largo plazo, puede dar lugar a una democracia más anémica. Por el otro, la continuidad productiva reduce la necesidad de inversiones y desafíos iniciales, pero puede obturar la innovación. Finalmente, la relevancia de la acción estatal nos advierte sobre las dificultades adicionales que este proceso de innovación social afronta en el caso del repliegue de la política públi- 
ca destinada al sector. Los casos aquí descriptos nos muestran que la recuperación de empresas es una vía posible de construcción de una economía más justa y solidaria. Aprender de esta vía colabora en ampliar los horizontes de su desarrollo.

\section{Referencias bibliográficas}

ALPEROVITZ, G. (2006): America Beyond Capitalism. New York: Wiley.

ALVES, G., BURDÍN, G. \& DEAN, A. (2016): "Workplace democracy and job flows. Journal of Comparative Economics", Elsevier, 44(2), 258-271, DOI: 10.1016/j.jce.2015.09.001.

ARCHENTI, N. (2007): "Estudio de caso/s". En Marradi, A., Archenti, N. y Piovani, J.I., Metodología de las Ciencias Sociales, Buenos Aires: Emecé editores, 237-246.

BALLADARES, C. (2012): "Sobre el trabajo a façon en las empresas recuperadas. Notas a partir de un caso de estudio", OSERA, 7, 1-17.

BIALAKOWSKY, A., ROBLEDO, G., GRIMA, J.M., ROSENDO, E. y COSTA, M.I. (2004): "Empresas recuperadas: cooperación y conflicto en las nuevas formas de autogestión de los trabajadores", Revista Venezolana de Gerencia, (9)26, 229-253, DOI: 10.31876/revista.v9i26.9755.

BURDIN, G. (2014): "Are Worker-Managed Firms More Likely to Fail Than Conventional Enterprises? Evidence from Uruguay”, ILR Review, 67(1), 202-238, DOI: 10.1177/001979391406700108.

CALLOWAY, C. (2016): "Autorregulación de los colectivos autogestivos de trabajadores/as", Revista Idelcoop, 218, 11-30.

CHOSCO DÍAZ, G.C., FARDELLI CORROPOLESE, C. y ANZOÁTEGUI, M. (2017): "El desarrollo organizacional sustentable de una empresa recuperada: procesos de resiliencia, identidad cooperativa, eficiencia e inclusión social", Revista Argentina de Investigación en Negocios, 3(2), 59-70.

CICOPA (2017a): Cooperatives and employment: Second Global Report. Contribution of cooperatives to decent work in the changing world of work, Bruselas: CICOPA.

CICOPA (2017b): Informe mundial: Cooperativas en la industria y los servicios 2015-2016, Bruselas: CICOPA.

CORAGGIO, J.L. (2008): "La sostenibilidad de los emprendimientos de la economía social y solidaria", Revista Otra Economía, (II)3, 41-57. 
COSTA ÁLVAREZ, C. (2008): Empresas recuperadas ¿democratización versus mercado?: Análisis de las tensiones entre autonomía y capital en el caso de la Cooperativa de Trabajo metalúrgica "Los Constituyentes". (Tesis de Licenciatura), Facultad de Humanidades y Ciencias de la Educación, Universidad Nacional de La Plata, Buenos Aires.

DE SOUSA SANTOS, B. y RODRÍGUEZ, C. (2011): "Para ampliar el canon de la producción", En: De Sousa Santos, B. (org.), Producir para vivir: los caminos de la producción no capitalista, México: Fondo de Cultura Económica, 15-61.

DEAN, A. (2014): ¿Las cooperativas de trabajadores degeneran?, Documento de Trabajo 01/2014, Instituto de Economía, Facultad de Ciencias Económicas y de Administración, Universidad de la República, Uruguay.

DEUX MARZI, M.V. (2014): De la recuperación a la consolidación. Análisis y perspectivas del trabajo y sus formas de organización en procesos de recuperación de empresas Argentina, 2000-2010. (Tesis de Doctorado en Ciencias Sociales no publicada), Facultad de Ciencias Sociales, Universidad de Buenos Aires, Buenos Aires.

FAJN, G. (coord.) (2003): Fábricas y empresas recuperadas. Protesta social, autogestión y rupturas en la subjetividad, Buenos Aires: Centro Cultural de la Cooperación.

FERNÁNDEZ ÁLVAREZ, M.I. (2007): "En defensa de la fuente de trabajo: demandas y prácticas de movilización en una empresa recuperada de Buenos Aires", Avá, 11, 63-86.

FERNÁNDEZ ÁLVAREZ, M.I. (2012): "Ocupar, resistir, producir... sostener. El problema de la sustentabilidad en las experiencias de gestión colectiva del trabajo", Revista del OSERA, 7, 1-13.

FERNÁNDEZ ÁLVAREZ, M.I. (2017): La política afectada: experiencia, trabajo y vida cotidiana en Brukman recuperada, Rosario: Prohistoria Ediciones.

HINTZE, S. (2013): "Las políticas públicas de promoción del trabajo asociativo autogestionado en América Latina", Revista del OSERA, 9.

HINTZE, S. (2018): "El trabajo en cooperativas en la Argentina del siglo XXI." En: Grassi, E. y Hintze, S. (coords.), Tramas de la desigualdad. Las políticas y el bienestar en disputa, Buenos Aires: Prometeo, 271-319.

HOPP, M. (2017): "Transformaciones en las políticas sociales de promoción de la economía social y del trabajo en la economía popular en la argentina actual", Cartografías del Sur. Revista de Ciencias, Arte y Tecnología, 6, 19-41, DOI: 10.35428/cds.v0i6.86.

HUDSON, J.P. (2011): Acá no me manda nadie: empresas recuperadas por obreros 2000-2010, Buenos Aires: Ediciones Tinta Limón.

INDEC (2018a): Informes Técnicos. Vol. 2, no 234, Buenos Aires: Instituto Nacional de Estadística y Censos. 
INDEC (2018b): Cuentas nacionales. Vol. 2, no 21, Buenos Aires: Instituto Nacional de Estadística y Censos.

INDEC (2018c): Informe de avance del nivel de actividad. Tercer trimestre de 2018, Buenos Aires: Instituto Nacional de Estadística y Censos.

ITZIGSOHN, J. y REBÓN, J. (2015): "The Social Bases of the Solidarity Economy: Transformative Possibilities in the global South", $4^{\text {th }}$ Annual Conference of the Sociology of Development, Brown University.

KASPARIAN, D. (2017): Lucha ¿sin patrón? Un estudio sobre la configuración de la conflictividad de trabajo en empresas recuperadas y cooperativas del Programa Argentina Trabaja. (Tesis de Doctorado en Ciencias Sociales no publicada), Facultad de Ciencias Sociales, Universidad de Buenos Aires, Buenos Aires.

MORALES, A.C., MONZÓN, J.L. y CHAVES, R. (2003): "La empresa autogestionada en retrospectiva". En: Morales, A.C., Monzón, J.L. y Chaves, R. (Edit.), Análisis económico de la empresa autogestionada, Valencia: CIRIEC-España, 7-45.

MORUNO, J. (2018): No tengo tiempo. Geografías de la precariedad, Madrid: Ediciones Akal.

MOYANO FUENTES, J., PUIG BLANCO, F. y BRUQUE CÁMARA, S. (2008): "Los determinantes de la competitividad en las cooperativas", CIRIEC-España, Revista de Economía Pública, Social y Cooperativa, 61, 233-249.

NEIMAN, G. y QUARANTA, G. (2006). "Los estudios de caso en la investigación sociológica". En Vasilachis de Gialdino, I. (coord.), Estrategias de investigación cualitativa, Barcelona: Editorial Gedisa, 213-237.

OSTROM, E. (2015): Governing the Commons: The evolution of institutions for collective action, Reissue edition. Cambridge: Cambridge University Press, DOI: 10.1017/CBO9781316423936.

PALOMINO, H. (coord.) (2003): "El movimiento de trabajadores de empresas recuperadas", Revista Sociedad, 20/21, 125-146.

PASTORE, R. (2006): Diversidad de trayectorias, aproximación conceptual y pluralidad de proyectos de la Economía Social, Documento 54, CESOT, Facultad de Ciencias Económicas, Universidad de Buenos Aires.

PERBELLINI, M. (2016): Empresa, organización del trabajo e identidad laboral. Estudio de las empresas recuperadas por sus trabajadores en su etapa de consolidación: análisis de dos empresas recuperadas del área del Gran Rosario. (Tesis de Doctorado en Ciencias Sociales no publicada). Facultad de Ciencias Sociales, Universidad de Buenos Aires, Buenos Aires.

PETRIELLA, A. (1998): "Nuevas preguntas y nuevas respuestas del movimiento cooperativo a fin de siglo.", Revista de Idelcoop, 115. 
PIZZI, A. y BRUNET ICART, I. (2014): "Autogestión obrera y movilización social. El caso de las empresas recuperadas argentinas en la Ciudad de Buenos Aires y Provincia de Buenos Aires", Latin American Research Review, 49 (1), 39-61, DOI: 10.1353/lar.2014.0005.

POLANYI, K. (2007): La gran transformación. Crítica del liberalismo económico, Buenos Aires: Fondo de Cultura Económica.

PROGRAMA FACULTAD ABIERTA (2010): Informe del Tercer Relevamiento de Empresas Recuperadas por sus trabajadores. Las empresas recuperadas en la Argentina. 2010, Buenos Aires: Facultad de Filosofía y Letras, Universidad de Buenos Aires.

PROGRAMA FACULTAD ABIERTA (2018): Las empresas recuperadas por los trabajadores en el gobierno de Mauricio Macri. Estado de situación a octubre de 2018, Buenos Aires: Facultad de Filosofía y letras, Universidad de Buenos Aires.

PUENTES POYATOS, R. y VELASCO GÁMEZ, M.M. (2009): "Importancia de las sociedades cooperativas como medio para contribuir al desarrollo económico, social y medioambiental, de forma sostenible y responsable", REVESCO, Revista de Estudios Cooperativos, 99, 104-129.

QUIJANO, A. (2011): “¿Sistemas alternativos de producción?”. En: De Sousa Santos (org.), Producir para vivir. Los caminos de la producción no capitalista, México: Fondo de Cultura Económica, 369-389.

REBÓN, J. (2007): La empresa de la autonomía. Trabajadores recuperando la producción, Buenos Aires: Colectivo Ediciones-Ediciones Picaso.

REBÓN, J. (2017): "Las empresas recuperadas por sus trabajadores en Argentina como forma socioproductiva", Revista Iberoamericana de relaciones laborales, 35, 7-22, DOI: 10.33776/trabajo. v35i0.3474.

REBÓN, J. y KASPARIAN, D. (2018): "El poder social en la producción. Una aproximación a partir de las empresas recuperadas por sus trabajadores", De Prácticas y discursos. Cuadernos de Ciencias Sociales, 7 (10), 9-33, DOI: 10.30972/dpd.7103520.

REBÓN, J., KASPARIAN, D. yHERNÁNDEZ, C. (2016): "The social legitimacy of recuperated enterprises in Argentina", Socialism \& Democracy, 30 (3), 37-54, DOI: 10.1080/08854300.2016.1214006.

SABÍN GALÁN, F., FERNÁNDEZ CASADEVANTE, J.L. y BANDRÉS DE LUCAS, I. (2013): "Factor C: Factores de resistencia de las microempresas cooperativas frente a la crisis y recomendaciones para un fortalecimiento cooperativo del sector de lo social", Revista vasca de economía social = Gizarte ekonomiaren euskal aldizkaria, 9, 75-100.

SALGADO, R. (2012): Los límites de la igualdad. Cambio y reproducción social en el proceso de recuperación de empresas por sus trabajadores, (Tesis de Doctorado en Ciencias Sociales no publicada), Facultad de Ciencias Sociales, Universidad de Buenos Aires, Buenos Aires. 
SALVIA, A. (2007): "Consideraciones sobre la transición a la modernidad, la exclusión social y la marginalidad económica" En: Salvia, A. y Chávez Molina, E. (comps.), Sombras de una marginalidad fragmentada, Buenos Aires: Miño Dávila Editores, 25-65.

SINGER, P. (2011): "La reciente resurrección de la economía solidaria en Brasil". En: De Sousa Santos, B. (org.), Producir para vivir: los caminos de la producción no capitalista, México: Fondo de Cultura Económica, 63-102.

STAKE, R.E. (2013): "Estudios de casos cualitativos". En: N.K. Denzin, Y.S. Lincoln (comps.), Manual SAGE de Investigación Cualitativa Vol. III: Estrategias de Investigación Cualitativa, Barcelona: Editorial Gedisa, 154-197.

SUPERVIELLE, M. (2017): "Criterios para la evalución de los emprendimientos cooperativos y autogestionarios. Una aproximación metodológica", El Uruguay desde la sociología, 15, 229-242.

TILLY, Ch. y WOOD, L. (2010): Los movimientos sociales 1768-2009, Madrid: Editorial Crítica.

VÁZQUEZ, G. (2010): "El debate sobre la sostenibilidad de los emprendimientos asociativos de los trabajadores autogestionados", Revista de Ciencias Sociales de la Universidad Nacional de Quilmes, 18, 97-121.

VÁZQUEZ, G. (2014): “¿Son sostenibles los emprendimientos asociativos de trabajadores autogestionados? Algunas reflexiones a contramano del sentido común", Voces en el Fénix, 37, 130-137.

VUOTTO, M. (1994): "Paradojas de la organización cooperativa" En: Giarraca, N. (comp.), Acciones colectivas y organización cooperativa. Reflexiones y estudios de caso, Buenos Aires: Centro Editor de América Latina.

WILLIAMS, M. (2014): "The solidarity economy and social transformation". En: Satgar, V. (comp.), The solidarity economy alternative: emerging theory and practice, Durban: University of KwaZulu-Natal Press, 37-63.

WRIGHT, E.O. (2010): Preguntas a la desigualdad. Ensayos sobre análisis de clase, socialismo y marxismo, Bogotá: Editorial Universidad del Rosario.

WRIGHT, E.O. (2015): Construyendo utopías reales, Buenos Aires: Ediciones Akal. 